\title{
A single-stage posterior approach with open reduction and pedicle screw fixation in subaxial cervical facet dislocations
}

\author{
Jin Hoon Park, MD, PhD, ${ }^{1}$ Sung Woo Roh, MD, PhD, ${ }^{2}$ and Seung Chul Rhim, MD, PhD² \\ 'Department of Neurological Surgery, Gangneung Asan Hospital, University of Ulsan College of Medicine, Gangneung, Korea; \\ and ${ }^{2}$ Department of Neurological Surgery, Asan Medical Center, University of Ulsan College of Medicine, Seoul, Korea
}

\begin{abstract}
OBJECT The optimal treatment for cervical facet dislocations is controversial, but the generally accepted process recommends an initial closed reduction with the next step determined according to the success of the closed reduction and the presence of traumatic disc herniation. This study aimed to show the efficacy of a posterior approach performed with an open reduction and pedicle screw fixation with removal of disc particles, if required, in the management of subaxial cervical dislocations.
\end{abstract}

METHODS Between March 2012 and September 2013, 21 consecutive patients with cervical facet dislocations were enrolled. The affected levels were as follows: 4 at C3-4; 2 at C4-5; 5 at C5-6; and 10 at the C6-7 level. Seven patients had traumatic disc herniations. Closed reduction was not attempted; a prompt posterior cervical surgery was performed instead. After open reduction, pedicle screw fixation was performed. In cases with traumatic disc herniation, herniated disc fragments were excised via a posterolateral approach and successful decompressions were determined by postoperative MRI studies. Clinical outcomes were assessed using the American Spinal Injury Association (ASIA) grading system. Radiological outcomes were assessed by comparing the degree of subluxation and the angle of segmental lordosis between pre- and postoperative CT scans.

RESULTS All patients improved neurologically. The mean segmental angles improved from $7.3^{\circ} \pm 8.68^{\circ}$ to $-5.9^{\circ} \pm$ $4.85^{\circ}$. The mean subluxation improved from $23.4 \% \pm 16.52 \%$ to $2.6 \% \pm 7.19 \%$. Disc fragments were successfully removed from the 7 patients with herniated discs, as shown on MRI.

CONCLUSIONS Open reduction followed by pedicle screw fixation or posterolateral removal of herniated disc fragments is a good treatment option for cervical facet dislocations.

http://thejns.org/doi/abs/10.3171/2014.11.SPINE14805

KEY WORDS cervical facet dislocation; closed reduction; open reduction; cervical pedicle screw; disc herniation; posterior approach; surgical technique

$\mathrm{T}$ HE choice of a surgical approach for cervical facet dislocation is variable and depends on a number of factors including the patient's neurological status, the presence of traumatic disc herniation, the success of closed reduction, uni- or bilateral facet dislocation, the presence of vertebral body fractures, and the experience and training of the surgeon. ${ }^{5,15}$ Although there is no gold standard for the treatment of cervical facet dislocations, a general consensus has emerged. This recommends an initial closed reduction with the next step determined according to the success of the closed reduction and the presence or absence of traumatic disc herniation. ${ }^{16}$
According to the American Association of Neurological Surgeons/Congress of Neurological Surgeons (AANS/ CNS) medical evidence-based guidelines on the Management of Acute Cervical Spine and Spinal Cord Injuries, published in 2013, closed reduction of fracture and dislocation injuries of the cervical spine appears to be safe and effective in awake patients. ${ }^{8}$ However, controversies remain regarding whether a closed reduction should be performed and about its safety. In addition, most spine surgeons agree that a closed reduction should not be attempted in an obtunded patient. ${ }^{15}$ For patients with failed closed reductions and disc herniation, an anterior cervical approach could

ABBREVIATIONS AANS/CNS = American Association of Neurological Surgeons/Congress of Neurological Surgeons; $A$ SIA $=$ American Spinal Injury Association; VA $=$ vertebral artery.

SUBMITTED August 11, 2014. ACCEPTED November 19, 2014.

INCLUDE WHEN CITING Published online April 24, 2015; DOI: 10.3171/2014.11.SPINE14805.

DISCLOSURE The authors report no conflict of interest concerning the materials or methods used in this study or the findings specified in this paper. 
be considered because this approach enables easy decompression of the herniated disc. However, a successful reduction using an anterior approach may not be possible in some cases. ${ }^{21}$ Reductions can be achieved with less effort and with better alignment via a posterior approach. ${ }^{5}$

We previously demonstrated the safety and efficacy of subaxial pedicle screw placement even when using a freehand technique. ${ }^{18}$ Here, we describe the efficacy of a single-stage posterior approach with open reduction, removal of herniated disc fragments, and pedicle screw fixation for management of cervical facet dislocations.

\section{Methods \\ Study Design}

Between March 2012 and September 2013, 21 consecutive patients (18 men and 3 women, with a mean age of 45.5 years [range 23-64 years]) were enrolled in this study, which was approved by the institutional review board of Gangneung Asan Hospital. Their initial diagnosis was a single-level subaxial cervical fracture and dislocation with spinal cord compression. The affected levels were as follows: 4 at the $\mathrm{C} 3-4 ; 2$ at the $\mathrm{C} 4-5 ; 5$ at the C5-6; and 10 at the C6-7 level. There were 16 unilateral facet dislocations and 5 bilateral facet dislocations (Table 1). All patients underwent preoperative MRI and CT scans with vertebral artery (VA) angiography. The mean followup duration was 18.2 months, and the minimum follow-up duration was 12 months. Initial MRI scans showed that spinal cord compression correlated with weakness of patients' extremities. Preoperative MRI scans identified 7 patients with traumatic disc herniation (Fig. 1A) and 14 patients without disc herniation. In the cases with traumatic disc herniation the location of the disc particle was carefully identified on the preoperative axial MR image. Four disc particles were displaced dominantly to one side, and were related to 3 unilateral dislocations and 1 bilateral dislocation. The other 3 particles were diffusely and bilaterally herniated without any dominant direction, and were related to 1 unilateral dislocation and 2 bilateral dislocations (Fig. 1B and C). Three cases of comminuted facet fracture, 2 cases of superior articular process fracture, 5 cases of inferior articular process fracture, and 3 cases of body fracture were seen on the CT scans.

Closed reductions were not attempted; instead posterior cervical surgeries were performed promptly following the MRI and CT scans (Fig. 2). For 2 patients exhibiting low systolic blood pressure below $90 \mathrm{~mm} \mathrm{Hg}$ despite the use of inotropics, and who had American Spinal Injury Association (ASIA) Grade A, surgery was delayed and these patients remained in the intensive care unit until their vital signs stabilized. All surgeries were performed on admission or the next day. Steroid treatment was administered for 24 or 48 hours in all the patients except those with ASIA Grade D.

\section{Surgical Procedures}

Patients were placed in the prone position and GardnerWells tongs were applied with 3 or 5 lbs of traction to allow a maximally horizontal head position. Motor evoked potential monitoring was used throughout the procedure. The motor evoked potential monitoring was not performed for patients with a complete cervical cord injury. After exposure, manual reductions were attempted with a slight elevation of the upper level of the spinous process with a Kocher clamp and simultaneous lifting of the inferior articular process by applying leverage force with a curet. All patients achieved a successful reduction. Next, index-level bilateral pedicle screw fixation was performed with a free-hand technique. Usually, a 3.5-mm-diameter and $30-\mathrm{mm}$-long screw and a $3.5-\mathrm{mm}$ titanium rod were used. As described previously, the most important factors for safe and accurate placement of cervical pedicle screws are the planning of the screw entry point by using information from the preoperative $\mathrm{CT}$ scan; the achievement of an adequate medial angle for screw insertion through the use of a curved and small-sized pedicle probe; the ability to detect the pedicle breach with a ball-tip probe; the proper conversion to a lateral mass screw when a breach is detected; and the ability to interpret the intraoperative anterior-posterior radiographic images properly after screw insertion. We followed the technical steps detailed above for the safe placement of the cervical pedicle screws. ${ }^{18}$

We identified the status of the VA (such as the presence of a traumatic occlusion [ 4 cases in our series], patency, and the dominant side) with CT angiography before the operation. We placed pedicle screws on the dominant VA side more carefully. We considered the possibility of skipping a screw at the index level or a lateral mass screw conversion, if the dominant VA side screw did not match the above criteria. However, there was no case in which we needed to skip a screw at the index level in our series.

In cases involving disc herniation, we performed decompression with a Kerrison rongeur and match-head type bur until the dura mater, root, and disc space were exposed. We performed a unilateral removal of the lamina

TABLE 1. Demographic data in 21 patients who had single-level fracture and dislocation with spinal cord compression

\begin{tabular}{|c|c|c|c|c|c|c|c|c|c|c|c|c|}
\hline \multirow[b]{2}{*}{ Level } & \multirow{2}{*}{$\begin{array}{l}\text { No. of } \\
\text { Pts }\end{array}$} & \multirow{2}{*}{$\begin{array}{l}\text { No. of Bilat/Unilat } \\
\text { Facet Dislocations }\end{array}$} & \multicolumn{4}{|c|}{ Fracture Type } & \multirow{2}{*}{$\begin{array}{c}\text { Disc } \\
\text { Herniation }\end{array}$} & \multicolumn{5}{|c|}{ No. w/ Preop ASIA Grade } \\
\hline & & & Comminuted & Sup Articular & Inf Articular & Body & & $A$ & $B$ & $\mathrm{C}$ & $\mathrm{D}$ & $\mathrm{E}$ \\
\hline C3-4 & 4 & $1 / 3$ & 1 & 0 & 2 & 0 & 1 & 2 & 1 & 0 & 1 & 0 \\
\hline C4-5 & 2 & $0 / 2$ & 0 & 0 & 0 & 0 & 1 & 0 & 0 & 1 & 1 & 0 \\
\hline C5-6 & 5 & $0 / 5$ & 0 & 2 & 1 & 1 & 0 & 1 & 0 & 1 & 3 & 0 \\
\hline C6-7 & 10 & $4 / 6$ & 2 & 0 & 2 & 2 & 5 & 2 & 0 & 2 & 6 & 0 \\
\hline Total & 21 & $5 / 16$ & 3 & 2 & 5 & 3 & 7 & 5 & 1 & 4 & 11 & 0 \\
\hline
\end{tabular}

$\operatorname{lnf}=$ inferior; pts = patients; sup = superior. 

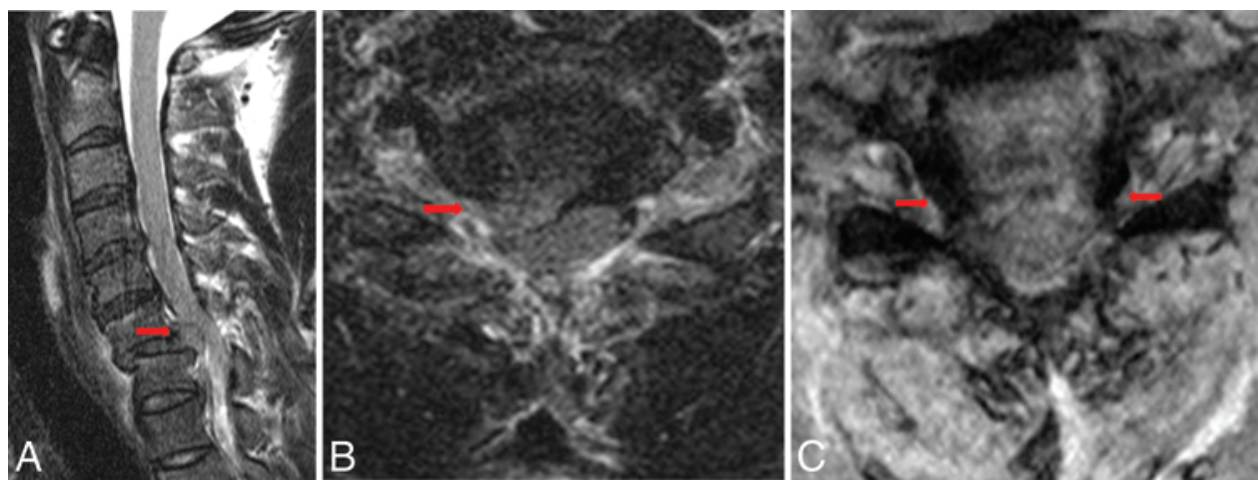

FIG. 1. A: Sagittal T2-weighted MR image of a 40-year-old male patient with an ASIA Grade D spinal cord function. The diagnosis was bilateral facet dislocation and traumatic disc herniation (red arrow). B: Axial T2-weighted MR image of the same patient. The disc particle is displaced dominantly to the right side (red arrow). C: Axial T2-weighted MR image of a 60-year-old male patient with an ASIA Grade C spinal cord function and bilateral facet dislocation at the C6-7 level. The disc particle is diffusely and bilaterally herniated without any dominant direction (red arrows). Figure is available in color online only.

and inferior articular process in 4 cases in which disc particles were displaced dominantly to one side, but bilateral decompression was needed in the other 3 cases. After bone decompression and identifying the dura of the spinal cord and root, we performed anulotomy on the lateral side of the dura. This procedure was done with root retraction, but we did not retract the spinal cord. With a lateral side discectomy, we could create a small space to push a reverse-angled curet most carefully in front of the dura. Despite using the foregoing procedure through a unilateral
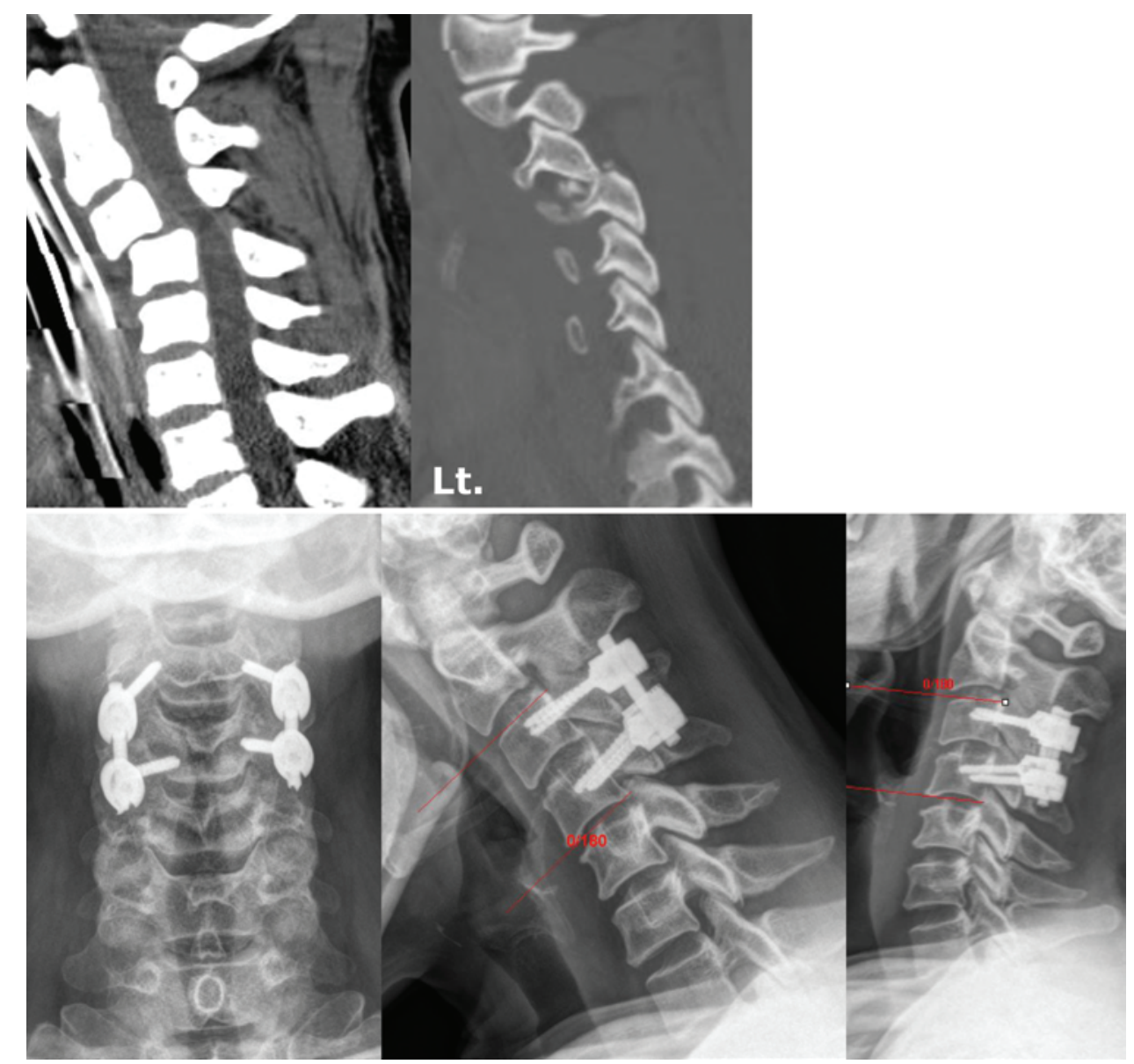

FIG. 2. Upper Row: Sagittal CT images of a 46-year-old female patient with an ASIA Grade B spinal cord function. Left unilateral facet dislocation and a superior articular process fracture are visible. Lower Row: Radiographs obtained in the same patient with a subsequent ASIA Grade D spinal cord function. Flexion and extension radiographs showed no instability at 12 months postoperatively. Figure is available in color online only. 


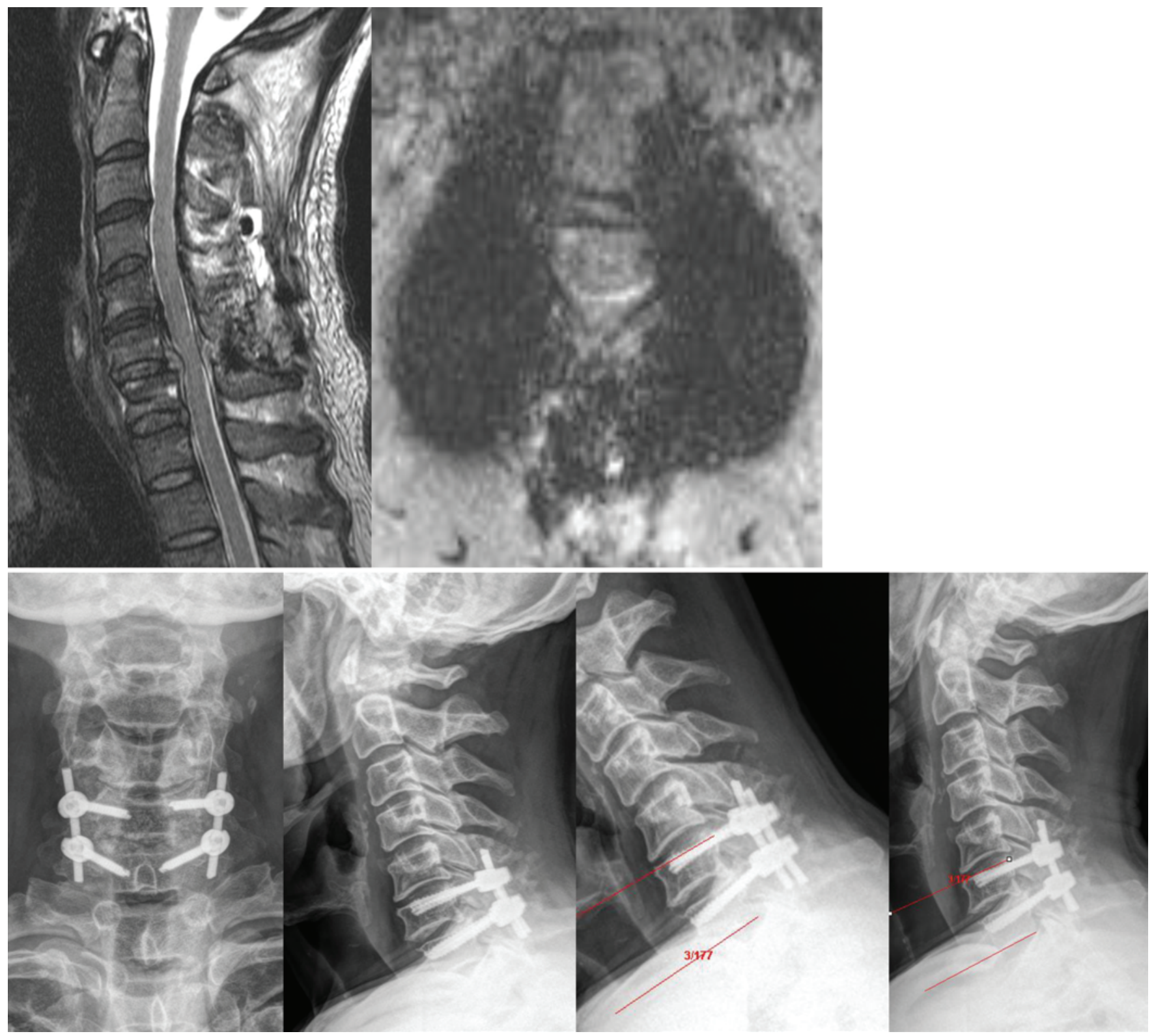

FIG. 3. Upper Row: Sagittal and axial T2-weighted MR images of a 40-year-old male patient after surgery due to a C6-7 level bilateral facet dislocation with ASIA Grade D spinal cord function. A preoperative right-side displaced disc herniation was partially removed, and the decompressed spinal cord can be observed. The patient's neurological status improved to ASIA Grade E after surgery. Lower Row: Dynamic radiographs obtained in the same patient showed no instability at 12 months postoperatively. Figure is available in color online only.

or bilateral side, removal of a deeply located disc particle was not easy. We believed that aggressive removal of the entire herniated disc particle was not necessary, because reduction is a key goal of surgery in cervical dislocation injury, as Abumi et al. previously described. ${ }^{2}$ Sometimes, because of a pressure gradient, the disc particle came out as soon as decompression was finished. Remnant particles or particles that did not come out due to the pressure gradient were removed in a posterolateral direction at the lateral side of the dura by using a reverse-angled curet.

In patients who did not show disc herniation, laminectomy was not performed to preserve the fusion bed.
In cases in which posterior disc removal was performed during surgery, we identified when decompression was sufficient with a postoperative MRI study. Although there was ventral remnant disc compression, a dorsal high-signal space could be seen indicating CSF on the axial MR image. Thus, we believed that the spinal cord was sufficiently decompressed based on this MRI finding (Fig. 3 upper row). Only in cases in which the MRI study showed sustained severe spinal cord compression would anterior additional surgery be considered.

Three of the 4 patients with C3-4 level injury required a tracheostomy and longer hospital stays than the other 18 

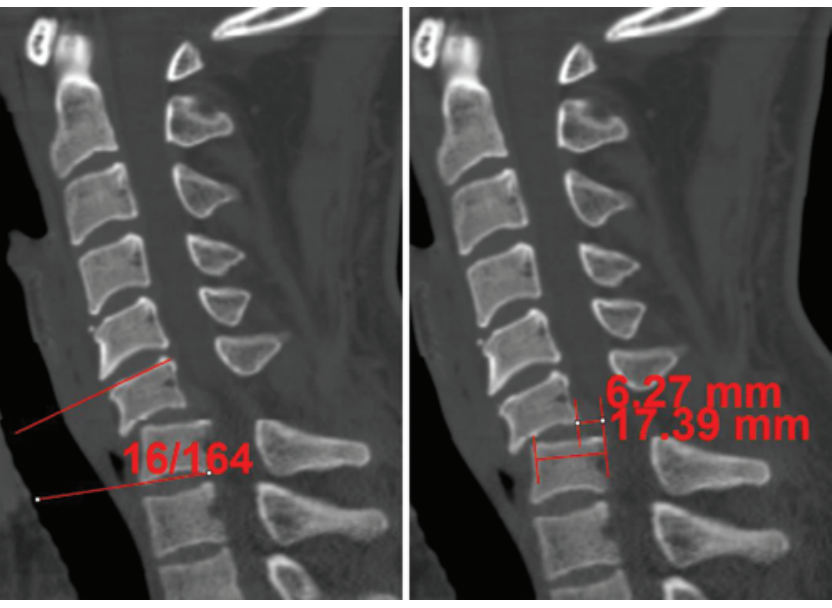

FIG. 4. Left: Segmental angle measured on a midsagittal CT image with $16^{\circ}$ kyphosis. Right: Subluxation measured on a midsagittal CT image displays $36.1 \%(6.27 / 17.39 \mathrm{~mm})$ subluxation. Figure is available in color online only.

patients, who were typically discharged or transferred to the Department of Rehabilitation Medicine 5 to 10 days postoperatively. Postoperative CT scans were performed for all patients. Lateral pedicle wall perforation was analyzed. ${ }^{18}$ A Philadelphia brace was recommended for 2 months. Radiographs, including a dynamic lateral image follow-up series, were obtained at 1, 3, 6, and 12 months postoperatively. Instability at the fused level was analyzed by the change of intervertebral angle between flexion and extension lateral images (Fig. 3 lower row). Clinical outcomes were analyzed using the ASIA grading system, comparing preoperative and 12-month postoperative data. Radiological outcomes were assessed by comparing the amount of subluxation and the angle of segmental lordosis between pre- and postoperative midline sagittal CT images (Fig. 4).

\section{Results}

There were 5, 1, 4, and 11 patients with an ASIA grade of A, B, C, and D, respectively, before their operations. All patients with Grade A remained at that grade after surgery. All Grade B and C patients improved to Grade D after surgery, and all Grade D patients improved to Grade E (Table 2). There was no patient who complained of a worsening of symptoms. Lateral mass screw conversion occurred in 5 screws $(5 / 84,6 \%)$ and a Grade 1 lateral pedicle wall perforation occurred in 5 screws $(5 / 79,6.3 \%)$. There was no medial or sagittal wall perforation and no complete vertebral foramen occlusion. No patients showed symptoms related to VA stenosis after surgery. The mean segmental angle was $7.3^{\circ} \pm 8.68^{\circ}$ kyphosis preoperatively, which was corrected to $-5.9^{\circ} \pm 4.85^{\circ}$ lordosis postoperatively. The mean subluxation was $23.4 \% \pm 16.52 \%$ preoperatively, and $2.6 \% \pm 7.19 \%$ postoperatively. Eighteen patients achieved complete reduction, and 3 patients had partial but not complete reduction (Fig. 5).

Sufficient decompression by disc particle removal from all 7 patients with traumatic disc herniation was identified by postoperative MRI studies (Fig. 3 upper row). The mean duration of the operations was $133.3 \pm 33.42 \mathrm{~min}$ utes. All patients experienced an improvement in neurological outcome after surgery, with no surgical complications. No patient showed instability at the index level on the dynamic radiographs at the 12-month follow-up evaluation (Fig. 3 lower row).

\section{Discussion}

Cervical facet dislocations occur as a result of flexion and distraction forces (with or without rotational forces) acting on the subaxial cervical spine. Substantial controversy remains regarding the most appropriate management of these injuries. Many surgeons have traditionally recommended rapid realignment of the spine through closed traction reduction followed by an MRI and a spinal fixation. Others recommend an initial MRI session followed by treatment predicated on the findings. ${ }^{9,15}$ In our hospital, patients with cervical spinal injuries underwent immediate MRI in the emergency medical department. Emergency operating rooms are prepared, if possible, while the MRI is performed. We believe that our strategy of early surgery results in shorter hospital stays. Closed reductions can result in rapid neurological improvement if an anterior surgical approach is followed. ${ }^{14,22}$ However, in some cases neurological deterioration and an increased prevalence of disc herniation are reported after a closed reduction; thus, other authors have recommended that this procedure should only be performed on awake and cooperative patients. ${ }^{23,24} \mathrm{~A}$ rapid open reduction can be a good option for uncooperative patients with severe injuries.

The selection of anterior or posterior surgical approach-

TABLE 2. Changes in ASIA grade in 21 patients who had single-level fracture and dislocation with spinal cord compression

\begin{tabular}{lcccc}
\hline $\begin{array}{c}\text { ASIA } \\
\text { Grade }\end{array}$ & $\begin{array}{c}\text { No. of Pts w/ Each } \\
\text { ASIA Grade at Preop }\end{array}$ & $\begin{array}{c}\text { No. of Pts w/ } \\
\text { Disc Herniation }\end{array}$ & $\begin{array}{c}\text { No. of Pts w/ Bilat/Unilat } \\
\text { Facet Dislocation }\end{array}$ & $\begin{array}{c}\text { No. of Pts w/ Each ASIA } \\
\text { Grade at 12 Mos Postop }\end{array}$ \\
\hline A & 5 & 3 & $2 / 3$ & 5 \\
\hline B & 1 & 0 & $0 / 1$ & 0 \\
\hline C & 4 & 1 & $1 / 3$ & 0 \\
\hline D & 11 & 3 & $2 / 9$ & 5 \\
\hline E & 0 & 0 & 0 & 11 \\
\hline Total & 21 & 7 & $5 / 16$ & 21 \\
\hline
\end{tabular}




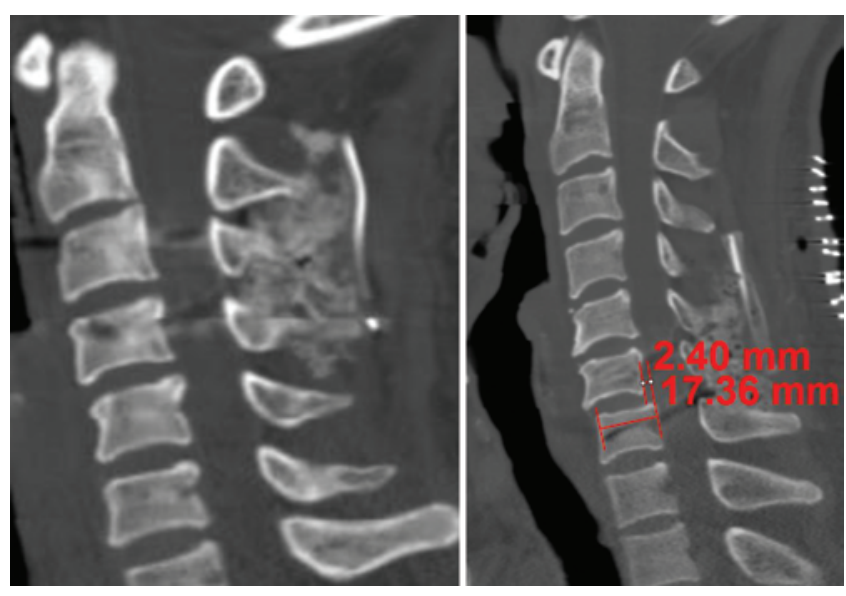

FIG. 5. Left: Postoperative midsagittal CT image demonstrating a completely reduced C3-4 level injury. Right: A partially reduced C6-7 level injury with $13.8 \%(2.40 / 17.36 \mathrm{~mm})$ subluxation remaining after surgery. Figure is available in color online only.

es is also controversial. However, previous studies report no differences between either approach in terms of neurological or radiological outcome. ${ }^{4,7}$ The anterior approach is a familiar method and can be useful for the easy removal of herniated discs. ${ }^{5,12,17,20,21}$ However, this approach is likely to be a better option when a closed reduction is successful. If the closed reduction fails or cannot be performed, then the possibility of failure of an open reduction and additional posterior surgery should be considered..$^{3,12,21}$ Thus, some surgeons recommend the use of an anterior buttress plate for easy reduction during the subsequent posterior approach. ${ }^{3}$

By contrast, the posterior approach is advocated because of easy reduction and improved postoperative alignment. ${ }^{5}$ In addition, because comminuted facet fractures or endplate fractures may result in a failed anterior surgery, additional or primary posterior surgery is recommended. ${ }^{11,19}$ In cervical trauma the biomechanical superiority of posterior instrumentation and a high stability of cervical pedicle screws have been reported. ${ }^{1,6,13}$ However, a significant disadvantage to the posterior approach for cervical facet dislocations is that it is difficult to remove the herniated disc posteriorly despite the reduction being easily achieved. Abumi et al. demonstrated that compression resulting from a traumatic herniated disc can be alleviated by a reduction and pedicle screw fixation. ${ }^{2}$ We have also shown that herniated discs can be removed posterolaterally. Bilateral or unilateral facet and lamina removal enables ventrally located disc particles to emerge due to a pressure gradient. A remnant or remaining disc particle can be gently removed in one piece with a small, reverse-angled instrument from the unilateral or bilateral side. This is a careful procedure that does not require retraction of the spinal cord, and thus no patients in our series experienced worse neurological outcomes after surgery.

As Abumi et al. previously reported, a great portion of traumatic herniated disc can be alleviated by successful reduction. ${ }^{2}$ We believe that aggressive and risky attempts to remove a deep, centrally located disc particle are not required. Good clinical and radiological outcomes were achieved with a single posterior approach and short operation times by using the above-described procedures and pedicle screw fixation. In addition, because the cervical pedicle screw fixates 3 vertebral columns simultaneously, stability can be achieved without anterior surgery. No patients in the present study required an additional anterior approach.

Steroid use for cervical spinal cord injury is not recommended according to the AANS/CNS medical evidencebased Guidelines on the Management of Acute Cervical Spine and Spinal Cord Injuries. ${ }^{10}$ Although steroids were used in the treatment of half of our patients, we believe that this was not related to any improvement of neurological outcomes.

The procedures used herein have several limitations. First, performing MRI studies rapidly is not always possible. Second, performing emergency surgery without a delay may not always be possible, because the time, place, staff, or other factors may not be suitable. In the cases described, the simple, free-hand pedicle screw insertion technique was useful for emergency surgery. ${ }^{18}$ Third, cervical pedicle screw fixation is a technically demanding procedure that not every surgeon can perform. Fourth, our current study design, with its small number of cases and short period of radiological follow-up, is insufficient to demonstrate the efficacy of this technique. Because of the short follow-up period in our study, we could not evaluate the success of radiological fusion and long-term construct durability. In addition, incomplete anatomical reduction or a conversion to lateral mass screw in some patients carries the increased likelihood of delayed radiological failure or chronic neck pain. Although there was no patient in our series who complained of neck pain greater than a visual analog scale score of 4 or who had radiological instability during the 1-year follow-up period, a longer follow-up and a larger number of cases are required to show the efficacy of our technique for cervical facet dislocation.

We believe that an initial attempt at a closed reduction as described by the AANS/CNS guidelines is an effective and safe method, followed by the previously recommended treatment for cervical facet dislocation. ${ }^{8,16}$ However, a single-staged posterior approach combined with pedicle screw fixation is a reasonable treatment option for patients who are poor candidates for closed reduction or who have experienced a failed closed reduction (with or without traumatic disc herniation).

\section{Conclusions}

Satisfactory clinical and radiological outcomes during a short follow-up period can be achieved for subaxial cervical dislocations via a single posterior approach with open reduction and pedicle screw fixation. Although an initial attempt at closed reduction is desirable after cervical dislocation, an immediate and single-stage posterior approach with open reduction and pedicle screw fixation, with or without posterolateral removal of traumatically herniated disc particle, is one treatment option for patients for whom closed reduction is not an appropriate intervention. 


\section{References}

1. Abumi K, Ito M, Sudo H: Reconstruction of the subaxial cervical spine using pedicle screw instrumentation. Spine (Phila Pa 1976) 37:E349-E356, 2012

2. Abumi K, Shono Y, Kotani Y, Kaneda K: Indirect posterior reduction and fusion of the traumatic herniated disc by using a cervical pedicle screw system. J Neurosurg 92 (1 Suppl):30-37, 2000

3. Allred CD, Sledge JB: Irreducible dislocations of the cervical spine with a prolapsed disc: preliminary results from a treatment technique. Spine (Phila Pa 1976) 26:1927-1931, 2001

4. Brodke DS, Anderson PA, Newell DW, Grady MS, Chapman JR: Comparison of anterior and posterior approaches in cervical spinal cord injuries. J Spinal Disord Tech 16:229-235, 2003

5. Elizabeth MY, Ahmad N: Management of cervical facet dislocations: anterior versus posterior approach, in Vaccaro AR, Eck JC (eds): Controversies in Spine Surgery: Best Evidence Recommendations. New York: Thieme Publishers, 2010, pp 48-58

6. Fehlings MG, Cooper PR, Errico TJ: Posterior plates in the management of cervical instability: long-term results in 44 patients. J Neurosurg 81:341-349, 1994

7. Gelb DE, Aarabi B, Dhall SS, Hurlbert RJ, Rozzelle CJ, Ryken TC, et al: Treatment of subaxial cervical spinal injuries. Neurosurgery 72 (Suppl 2):187-194, 2013

8. Gelb DE, Hadley MN, Aarabi B, Dhall SS, Hurlbert RJ, Rozzelle CJ, et al: Initial closed reduction of cervical spinal fracture-dislocation injuries. Neurosurgery 72 (Suppl 2):73-83, 2013

9. Hart RA: Cervical facet dislocation: when is magnetic resonance imaging indicated? Spine (Phila Pa 1976) 27:116-117, 2002

10. Hurlbert RJ, Hadley MN, Walters BC, Aarabi B, Dhall SS, Gelb DE, et al: Pharmacological therapy for acute spinal cord injury. Neurosurgery 72 (Suppl 2):93-105, 2013

11. Johnson MG, Fisher CG, Boyd M, Pitzen T, Oxland TR, Dvorak MF: The radiographic failure of single segment anterior cervical plate fixation in traumatic cervical flexion distraction injuries. Spine (Phila Pa 1976) 29:2815-2820, 2004

12. Kim KH, Cho DC, Sung JK: The management of bilateral interfacetal dislocation with anterior fixation in cervical spine: comparison with combined antero-posterior fixation. J Korean Neurosurg Soc 42:305-310, 2007

13. Kim SM, Lim TJ, Paterno J, Park J, Kim DH: A biomechanical comparison of three surgical approaches in bilateral subaxial cervical facet dislocation. J Neurosurg Spine 1:108-115, 2004

14. Lee AS, MacLean JC, Newton DA: Rapid traction for reduction of cervical spine dislocations. J Bone Joint Surg Br 76:352-356, 1994
15. Lee JY, Nassr A, Eck JC, Vaccaro AR: Controversies in the treatment of cervical spine dislocations. Spine J 9:418-423, 2009

16. Nassr A, Lee JY, Dvorak MF, Harrop JS, Dailey AT, Shaffrey CI, et al: Variations in surgical treatment of cervical facet dislocations. Spine (Phila Pa 1976) 33:E188-E193, 2008

17. Ordonez BJ, Benzel EC, Naderi S, Weller SJ: Cervical facet dislocation: techniques for ventral reduction and stabilization. J Neurosurg 92 (1 Suppl):18-23, 2000

18. Park JH, Jeon SR, Roh SW, Kim JH, Rhim SC: The safety and accuracy of freehand pedicle screw placement in the subaxial cervical spine: a series of 45 consecutive patients. Spine (Phila Pa 1976) 39:280-285, 2014

19. Randle MJ, Wolf A, Levi L, Rigamonti D, Mirvis S, Robinson W, et al: The use of anterior Caspar plate fixation in acute cervical spine injury. Surg Neurol 36:181-189, 1991

20. Razack N, Green BA, Levi AD: The management of traumatic cervical bilateral facet fracture-dislocations with unicortical anterior plates. J Spinal Disord 13:374-381, 2000

21. Reindl R, Ouellet J, Harvey EJ, Berry G, Arlet V: Anterior reduction for cervical spine dislocation. Spine (Phila Pa 1976) 31:648-652, 2006

22. Sabiston CP, Wing PC, Schweigel JF, Van Peteghem PK, Yu W: Closed reduction of dislocations of the lower cervical spine. J Trauma 28:832-835, 1988

23. Vaccaro AR, Falatyn SP, Flanders AE, Balderston RA, Northrup BE, Cotler JM: Magnetic resonance evaluation of the intervertebral disc, spinal ligaments, and spinal cord before and after closed traction reduction of cervical spine dislocations. Spine (Phila Pa 1976) 24:1210-1217, 1999

24. Wimberley DW, Vaccaro AR, Goyal N, Harrop JS, Anderson DG, Albert TJ, et al: Acute quadriplegia following closed traction reduction of a cervical facet dislocation in the setting of ossification of the posterior longitudinal ligament: case report. Spine (Phila Pa 1976) 30:E433-E438, 2005

\section{Author Contributions}

Conception and design: Park. Acquisition of data: Park. Analysis and interpretation of data: Park. Drafting the article: Park. Critically revising the article: Roh. Reviewed submitted version of manuscript: Rhim, Roh. Approved the final version of the manuscript on behalf of all authors: Rhim. Administrative/technical/ material support: Park. Study supervision: Rhim, Park.

\section{Correspondence}

Seung Chul Rhim, Department of Neurological Surgery, Asan Medical Center, College of Medicine, University of Ulsan, 388-1 Pungnap-2dong, Songpa-gu, Seoul 138-736, Korea. email: scrhim@amc.seoul.kr. 